\title{
Validation and application of health utilities index in Chinese subjects with down syndrome
}

\author{
Winnie Ka Yan Mok, Wilfred Hing-Sang Wong, Gary Tsz Kin Mok, Yoyo Wing Yiu Chu, Frederick Ka Wing Ho, \\ Chun Bong Chow, Patrick Ip and Brian Hon-Yin Chung
}

\begin{abstract}
Objectives: The objectives of the study were (1) to validate the Chinese version of Health Utilities Index (HUI-Ch); (2) to examine the Health-related Quality of Life (HRQoL) of Chinese subjects with Down syndrome (DS); and (3) to study the impact of chronic health conditions on HRQoL of Chinese with DS.

Methods: The multiple choice questionnaire for scoring Health Utilities Index Mark 2 (HUI2) and Health Utilities Index Mark 3 (HUI3) was translated and validated. In addition to the HRQOL scores from HUI2 and HUI3, proxy-data on socio-demographics, and 10 common chronic health conditions for people with DS were collected and analyzed. Data analysis involves multiple imputation and multiple regression analysis to predict variations in HRQoL in relation to different factors. Lastly, a gradient interval was constructed on the number of chronic health conditions in relation to HRQOL.
\end{abstract}

Results: HUI-Ch was validated according to standard guidelines. People with DS were found to have a lower HRQoL as compared to the general population, with the majority categorized as moderate or severe on the scale. Behavioral and hearing problems on $\mathrm{HUI}$, and hearing problems on $\mathrm{HUI} 3$ were found to be statistically significant predictors of a lower HRQoL score. A significant gradient relationship existed showing when the number of health problems increased, the HRQoL scores decreased.

Conclusions: HUI-Ch is a valid instrument to assess HRQoL. It can have broad application in Chinese subjects with DS including the study of the impact of different chronic health conditions on their quality of life. The quantifiable nature of HUI-Ch will facilitate longitudinal study on the well-being of subjects with DS and evaluation of effectiveness of intervention programs in the near future.

Keywords: Down syndrome, Health-related Quality of Life, Health Utility Index, Chinese, Chronic health conditions

\section{Objectives}

Down syndrome (DS), also known as trisomy 21, is the most common chromosome abnormality characterized by having an extra copy of chromosome 21. Globally, the incidence ranges from 1 in 650 to 1000 , estimating the total number of people with DS to be 6 million [1,2]. In Hong Kong, a similar incidence rate of 1 in 767 live births was found [3].

Epidemiologic studies have identified people with DS to have an increased risk of chronic health conditions

\footnotetext{
*Correspondence: patricip@hku.hk; bhychung@hku.hk

Department of Paediatrics and Adolescent Medicine, Queen Mary Hospital, Li Ka Shing Faculty of Medicine, The University of Hong Kong, Hong Kong Special Administrative Region, People's Republic of China
}

including cardiac, endocrine, gastrointestinal, immunological, respiratory, musculoskeletal, as well as oncological diseases [4-10]. It has been suggested that people with DS has a unique aging profile, with premature onset and rapid progressing manifestation of age-related conditions such as menopause, sensory impairments, thyroid dysfunction, diabetes, sleep apnea, and Alzheimer's disease [11-20]. Their functional capability is limited due to mental impairment, affecting their learning abilities, verbal working memory, and receptive language $[21,22]$. Behavior problems such as impaired social development, impulsive behavior, poor judgment, and short attention span are also commonly observed amongst people with DS [1]. 
Health-related Quality of Life (HRQoL) is a multidimensional concept reflecting life quality related to physical, mental, emotional and social functioning. As defined by the World Health Organization (WHO), the HRQoL comprises of six domains: physical health, psychological well-being, level of independence, social relationships, environment, and personal beliefs. In subjects with DS, the diverse set of physical and development impairments is likely to adversely impact their HRQoL. As demonstrated by a study using the TNO-AZL Children's Quality of Life questionnaire, a significant deficit in HRQoL was observed in a group of 8-year-old children with DS as compared to a normative population [22]. Another study found that recurrent respiratory tract infections had a large adverse impact on the HRQoL of children with DS [23].

As the longevity of people with DS increased over the years, the life expectancy was observed to be around 60 years of age [10,13,24-26]. Published studies evaluating HRQoL of people with DS were so far limited and primarily focused on children, assessing only one disease group, and of western population. The HRQoL of adults with DS have not been well studied, and outcome measures may also be different in Chinese. Therefore, the objectives of this study were: 1 ) to validate the Chinese version of Health Utilities Index (HUI-Ch), 2) to determine the HRQoL of both adult and paediatric Chinese subjects with DS, and 3) to study the relationship between chronic health conditions and HRQoL of Chinese subjects with DS.

\section{Methods}

Two health-state classification systems, Health Utilities Index Mark 2 (HUI2) and Health Utilities Index Mark 3 (HUI3) were used to measure HRQoL. These instruments are non-disease specific index applicable to individuals over the age of 5 and have been shown to be responsive to various chronic diseases such as rheumatoid arthritis [27], type 2 diabetes [28], and stroke [29]. HUI2 and HUI3 are 2 independent yet complementary systems measuring HRQoL. Each of HUI2 and HUI3 includes a generic comprehensive health status classification system and a generic HRQoL utility scoring system. Outlines of the different attributes measured between the two HUI system were included in the Additional files.

The 15-multiple choice questionnaire allows scoring subjects according to HUI2 and HUI3. HUI2 describes an individual's functional health status using 7 health attributes (Sensation, Mobility, Emotion, Cognition, Self-Care, Pain and Fertility) distinguished by $3-5$ descriptive levels (see Additional file 1: Table S1) while HUI3 describes using 8 health single-attributes (Vision, Hearing, Speech, Ambulation, Dexterity, Emotion, Cognition and Pain) distinguished by $5-6$ descriptive levels (see Additional file 2: Table S2). A multiplicative scoring algorithm using the individual health attributes of HUI2 and HUI3 yield the multi-attribute utility scores, which is the numerical measurement for HRQoL. HRQoL score has an intervalscale property with score of 0.00 being conventional dead to 1.00 being in perfect health [30-35].

\section{Translation and validation of HUI (traditional Chinese version)}

English-language HUI questionnaire obtained from Health Utilities Inc. (HUInc) was translated into traditional Chinese language (HUI-Ch) for adaptation and use in Chinese population. The research team followed the stringent translation and adaptation procedures of HUI instrument in accordance to the guideline set out by HUInc. This included forward translation by an academic translator, followed by 2 backward translations by a board-certified genetic counselor and a research assistant independently. Discrepancies were identified, analyzed, and revised internally and reviewed by HUInc personnel as well as experts in the field to ensure linguistic equivalence between the original and translated version. Acceptability testing on 5 healthy Chinese adults was also conducted to ensure consistency between English and Chinese version of HUI.

Chinese subjects with DS were recruited in collaboration with the Hong Kong Down Syndrome Association (HKDSA). Staff of HKDSA invited parents or caregivers of people with DS to complete a questionnaire and a proxy version of the Chinese translated version of HUI at various activities hosted by HKDSA. Detailed explanations were provided to participants and their families before they signed the consent. Verbal instructions were provided to respondents on how to fill in the questionnaire and on the clarification of any unclear items. The study aimed at recruiting as many subjects as possible and the recruitment was carried out over the 6 months period from Dec 2012 to May 2013. The participants did not receive any incentives and none of them requested to leave the study. Because of varying intellectual ability of the people with DS, respondents were the parents or caregivers, whom provided answers in lieu of the individual with DS. An information sheet was provided to each participant and his/her family to clearly inform about the purpose and details of the survey and provide participant a contact phone number to reach our research team. Consent form was signed by each participant's family member before he/she joined the study. To protect participant's privacy, a unique study number (instead of personal ID number) was assigned to each participant and the data were all kept in a computer with protected password locked in our University office. 


\section{Measures}

Data on the HRQoL, DS subject's demographics, and chronic health conditions (as defined by local populationbased health survey [36]) were collected and used for analysis. Ten chronic health conditions more prevalent in DS [5,8,22,37-39] were selected and categorized into 2 groups, namely physical health problem and developmentalbehavioral problem. The five physical health problems included cardiac diseases, endocrine problems, growth problem, sleep disturbances, and chronic orthopedic bone/ joint problems. The five developmental-behavioral problems included behavior problems, speech problems, learning problems, hearing impairment/deafness, and vision problems. Respondents were asked to report if the health condition has been observed in the individual with DS.

\section{Data analysis}

HUI data were analyzed according to the manual provided by HUInc. The tabulated HRQoL scores were then categorized into 4 disability levels (none, mild, moderate, severe) as proposed by the HUI developers. Such categorization method has been validated as appropriate for assessing disability levels for comparison to general population [40]. The disability level descriptions are summarized in Additional file 3: Table S3. Missing data were treated using multiple imputations with 5 times imputations. Unpaired t-tests were used to test the univariate relationship between HRQoL scores and demographics and different chronic health conditions. Significant factors correlating to HRQoL scores were then put into multiple linear regression models. $\mathrm{R}$ statistical software version 3.0.1 was used for the analysis. A p-value with 2 -tail $<0.05$ was treated as significant. Exclusion criteria included non-Chinese and those individuals with DS under the age of 5 .

This study received ethics approval from the Institutional Review Board of the University of Hong Kong/ Hospital Authority Hong Kong West Cluster.

\section{Results}

\section{Characteristics of study population}

A total of 109 individuals with DS participated in this study. As summarized in Table 1, 79 (72\%) were adults while $30(28 \%)$ were aged 18 or below. Sixty-one (56\%) of participants were male. All were Chinese descendants; with $99 \%$ of them being Hong Kong permanent residents using Cantonese as their primary language. As the survey was proxy-assessed, we found that $89 \%$ of the respondents were mothers of the subject with DS, $6 \%$ were fathers, $4 \%$ were siblings, and $2 \%$ were other relatives.

\section{Self-reported chronic health conditions}

The self-reported chronic health conditions were categorized into physical health and developmental-behavioral
Table 1 Characteristics of subjects with Down syndrome

\begin{tabular}{|c|c|c|}
\hline & $\mathrm{n}$ & $\%$ \\
\hline \multicolumn{3}{|l|}{ Age (in years) } \\
\hline $5-18$ & 30 & $28 \%$ \\
\hline$>18$ & 79 & $72 \%$ \\
\hline \multicolumn{3}{|l|}{ Gender } \\
\hline Male & 61 & $56 \%$ \\
\hline Female & 48 & $44 \%$ \\
\hline \multicolumn{3}{|l|}{ Race } \\
\hline Chinese & 109 & $100 \%$ \\
\hline \multicolumn{3}{|l|}{ Hong Kong Resident Status: } \\
\hline Permanent resident & 108 & $99 \%$ \\
\hline Singly- non-permanent resident & 0 & $0 \%$ \\
\hline Doubly- non-permanent resident & 1 & $1 \%$ \\
\hline Non-residence & 0 & $0 \%$ \\
\hline \multicolumn{3}{|l|}{ Primary Language spoken: } \\
\hline Cantonese & 108 & $99 \%$ \\
\hline Putonghua & 1 & $1 \%$ \\
\hline \multicolumn{3}{|l|}{ Proxy-relation: } \\
\hline Mother & 97 & $89 \%$ \\
\hline Father & 6 & $6 \%$ \\
\hline Sibling & 4 & $4 \%$ \\
\hline Others & 2 & $2 \%$ \\
\hline
\end{tabular}

problems. Physical health problems included 10 (9\%) cardiac disease, 24 (22\%) endocrine problems, 27 (25\%) growth problems, 18 (17\%) sleep disturbance issues, and 11 (10\%) chronic orthopedic bone or joint problems. Developmental-behavioral problems included 18 (17\%) behavioral problems, 58 (53\%) speech problems, 55 (50\%) learning problems, 21 (19\%) hearing impairment or deafness, and 50 (46\%) vision problems.

\section{HRQoL analysis}

Categorization of HRQoL scores into disability level shown in Figure 1 illustrated that the majority of Chinese people with DS were in the 'severe' disability group. As shown in Table 2, analysis using unpaired $t$-test and multiple regression for both HUI2 and HUI3 showed that demographic factors (gender and age) and physical conditions did not affect their HUI2 and HUI3 HRQoL scores.

Evaluating the impact of different factors on HUI2 HRQoL scores indicated that those having developmentalbehavioral conditions (problems in behavioral $(p<0.01)$, speech $(\mathrm{p}=0.01)$, learning $(\mathrm{p}=0.04)$, hearing $(\mathrm{p}<0.01)$, and vision $(\mathrm{p}=0.03)$ ) had a significantly lower HUI2 HRQoL score. Among them, only behavior problems ( $\mathrm{p}=$ $0.04)$ and hearing problems $(p=0.03)$ were found to be significant indicators for a lower HRQoL score by multiple regression. We found lower HUI3 scores among those 


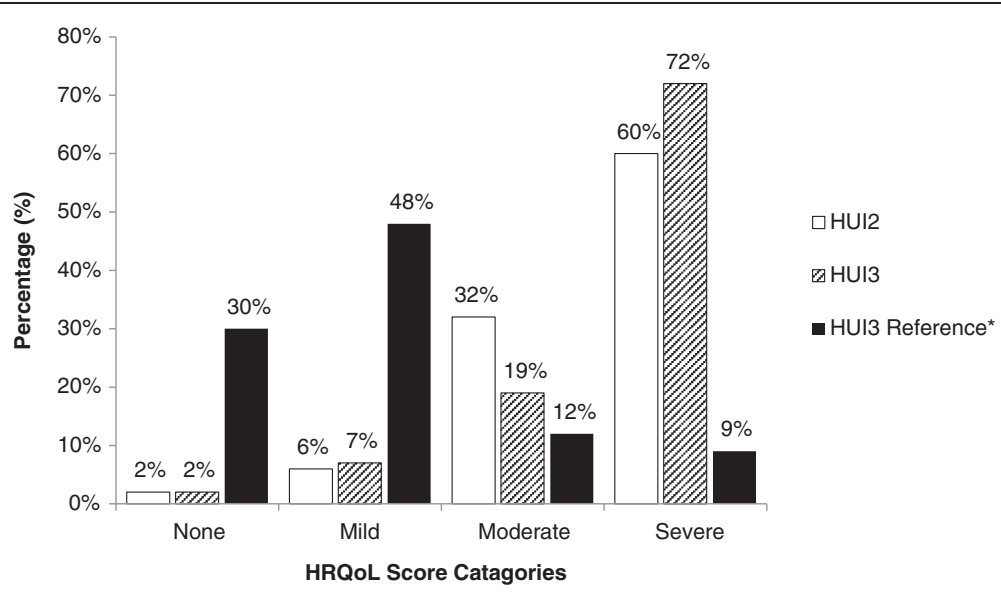

Figure 1 HUI2 and HUI3 HRQoL scores in individuals with DS ( $\mathbf{n = 1 0 9 ) . ~ * H U I 3 ~ R e f e r e n c e ~ S o u r c e : ~} 2005$ Canadian Community Health Survey, which represents the HRQoL of 18,271 Canadians with no chronic conditions at all [41].

who had all 5 developmental-behavioral conditions (problems in behavioral $(p=0.02)$, speech $(p<0.01)$, learning $(\mathrm{p}=0.01)$, hearing $(\mathrm{p}<0.01)$, and vision $(\mathrm{p}<0.01))$ and among those who had at least one physical conditions (endocrine problems $(\mathrm{p}=0.02)$ ). Hearing problem $(\mathrm{p}=0.03)$ was the only significant factor accounted for a lowered HRQoL score by multiple regression.

Figure 2 showed HUI2 and HUI3 in relation to increasing number of chronic health conditions the individuals with DS experienced. Both HUI2 and HUI3

Table 2 Chronic health conditions in HUI2/HUI3 scores

\begin{tabular}{|c|c|c|c|c|c|c|}
\hline & \multicolumn{3}{|l|}{ HUI2 } & \multicolumn{3}{|l|}{ HUI3 } \\
\hline & \multicolumn{2}{|c|}{ Two-sample $t$-test } & \multirow{2}{*}{$\begin{array}{l}\text { Multiple regression } \\
\text { p }\end{array}$} & \multicolumn{2}{|c|}{ Two-sample $t$-test } & \multirow{2}{*}{$\begin{array}{l}\text { Multiple regression } \\
\mathrm{p}\end{array}$} \\
\hline & Mean (SD) & $\mathrm{p}$ & & Mean (SD) & $p$ & \\
\hline \multicolumn{7}{|l|}{ Physical conditions } \\
\hline Endocrine problems & & 0.17 & - & & $0.02^{*}$ & 0.20 \\
\hline No & $0.74(0.15)$ & & & $0.59(0.26)$ & & \\
\hline Yes & $0.69(0.15)$ & & & $0.42(0.28)$ & & \\
\hline \multicolumn{7}{|c|}{ Developmental-behavioural conditions } \\
\hline Behavioural problems & & $<0.01^{*}$ & $0.04^{*}$ & & $0.02^{*}$ & 0.28 \\
\hline No & $0.75(0.14)$ & & & $0.58(0.27)$ & & \\
\hline Yes & $0.64(0.16)$ & & & $0.42(0.26)$ & & \\
\hline Speech problems & & $0.01^{*}$ & 0.47 & & $<0.01^{*}$ & 0.50 \\
\hline No & $0.77(0.15)$ & & & $0.65(0.26)$ & & \\
\hline Yes & $0.69(0.14)$ & & & $0.47(0.26)$ & & \\
\hline Learning problems & & $0.04^{*}$ & 0.94 & & $0.01^{*}$ & 0.54 \\
\hline No & $0.76(0.17)$ & & & $0.63(0.26)$ & & \\
\hline Yes & $0.71(0.13)$ & & & $0.48(0.27)$ & & \\
\hline Hearing problems & & $<0.01^{*}$ & $0.03^{*}$ & & $<0.01^{*}$ & $0.03^{*}$ \\
\hline No & $0.75(0.14)$ & & & $0.59(0.25)$ & & \\
\hline Yes & $0.64(0.16)$ & & & $0.39(0.28)$ & & \\
\hline Vision problems & & $0.03^{*}$ & 0.44 & & $<0.01^{*}$ & 0.35 \\
\hline No & $0.76(0.14)$ & & & $0.62(0.24)$ & & \\
\hline Yes & $0.70(0.16)$ & & & $0.47(0.29)$ & & \\
\hline
\end{tabular}

Base on the death to perfect health scale $(0.00-1.00)$.

${ }^{*}$ p-value $<0.05$. 


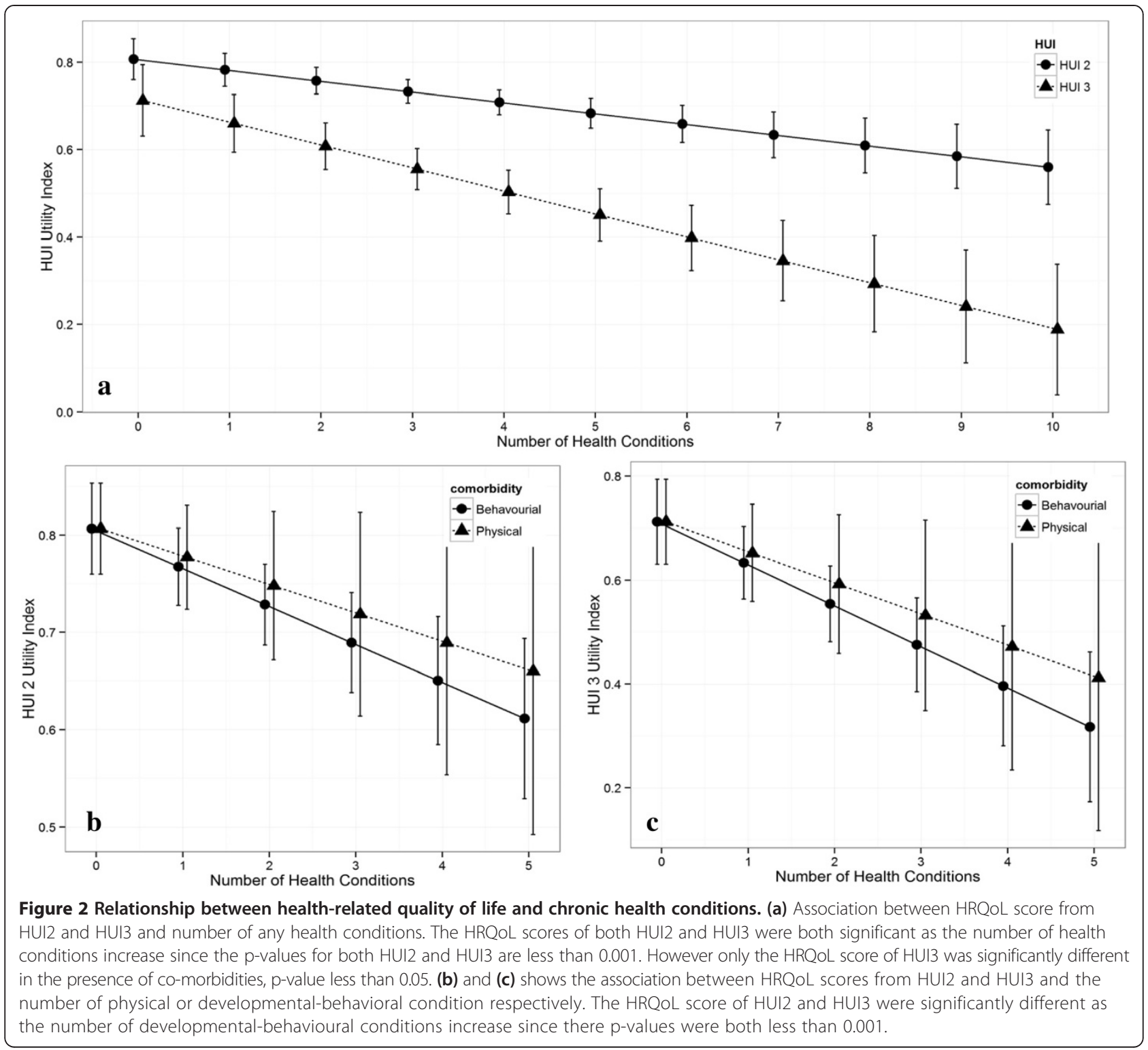

classification system yielded a statistically significant negative relationship where HRQoL scores decreased as the number of health problems increased. The extent of decrease detected is more sensitive in HUI3 than HUI2. Assessments of HUI2 and HUI3 in relation to increasing number of any of the 5 physical health problems or any of the 5 developmental-behavioral problems individually are represented in Figure 2b) and c). Worth to note, a greater inverse dosage effect was observed on HRQoL deficit as the number of developmental-behavioral conditions increased as compared to physical health problems. The negative linear relationship between number of chronic conditions and HRQoL was found to be significant $(\mathrm{p}<0.001)$ for developmental-behavioural conditions but not for physical health problems $(p>0.05)$ in both HUI2 and HUI3 classification method.

\section{Discussion}

The goal of this study was to develop and validate the use of HUI-Ch in the Chinese population and to investigate the HRQoL of people with DS in Hong Kong. We have described the process for translation of the HUI2 and HUI3 questionnaire into traditional Chinese and the validation process. HUInc has validated and approved more than 35 other languages so far, including languages such as German [42], Spanish [43] and French [44]. The standard translation process recommended by HUInc is a published guideline by Guillemin et al. on translation and cultural adaptation of HRQoL questionnaires [45]. Validation process was completed with direct oversight by HUI developers, and the HUI-Ch received final approval from the developers of HUI. 
The HUI instrument is a generic preference-scored system for measuring health status and HRQoL for a broad range of subjects. The sample of our study covers a broad age range, assessing the HRQoL of 109 people with DS from age of 5 and above. As compared to findings of local population health survey [36], we found a much higher occurrence rates of physical health and developmental-behavioral problems amongst DS subjects in this study, signifying that the chronic health conditions were more prevalent in DS. This study also demonstrated that the HRQoL of people with DS is less favorable than a reference group with no disability from a general population cohort without any reports of chronic illness [41]. When comparing to the HRQoL of different conditions found in past studies that used HUI, the HRQoL of subjects with DS in the current study is found to be generally lower. This can be seen in Table 3. Since the current study is the first HRQoL study using HUI both in Chinese and in people with DS, this makes it difficult to make direct comparison with other relevant studies and we were only able to compare with HRQoL of other patient groups in other countries. After publication, we will conduct further studies in local Chinese population in Hong Kong and this will allow us to compare findings among populations with different medical conditions and further confirm the validity of HUI-Ch.

Further analysis relating HRQoL and chronic health conditions found that none of the physical health issues assessed suggested significant negative association with HRQoL. In contrast, hearing and behavior problems were found to significantly decrease the HRQoL of people with DS, which is actually in line with the observations of many local parents of DS children and the previous quality of life studies on subjects with hearing impairment [52,53] and with behavioral problems [22]. In spite of the existing evidence linking developmental disabilities and impaired quality of life [22], there are so far lacking evidence on its impact on DS subjects. Our findings help to bridge this knowledge gap.

Additionally, a gradient relationship was observed, with increasing number of developmental-behavioral problems resulted in more deficit of HRQoL. This is an important finding on DS subjects which were not reported previously. Developmental issues such as sensory impairments (hearing, vision) may impair individual subject's ability to communicate, consequently provoking frustration and problem behaviors, as they are unable to express themselves. Thus, each additional developmental-behavioral problem would escalate the burden to individual subject with DS and reduce their quality of life. In addition, deteriorations in health may also be associated with an increase in aggressive behavior, particularly when there were communication difficulties in expressing underlying medical problems, as shown in previous studies on those with intellectual disabilities [54,55]. Thus, behavior problems could possibly be an indication for some undiagnosed illness, reflective by a lowered HRQoL.

Effective surveillance and appropriate interventions towards hearing impairment, behavioral problems and other relevant developmental-behavioral problems would certainly help to improve the quality of life of DS subjects. Currently, there are no health surveillance programs for adults with DS to assess their hearing or behavior problems. Health care professionals looking after subjects with DS should be alerted to look for these potential developmental-behavioral problems to minimize its adverse impact. Meanwhile, regular surveillance program

Table 3 Comparison of HUI3 scores in studies of different conditions

\begin{tabular}{|c|c|c|c|c|c|c|c|}
\hline & $\begin{array}{l}\text { Current study } \\
(n=109)\end{array}$ & $\begin{array}{l}\text { Tilford et al. } \\
2012[46] \\
(n=146)\end{array}$ & $\begin{array}{l}\text { Manuel et al. } \\
2002[47] \\
(n=8258)\end{array}$ & $\begin{array}{l}\text { Petrou et al. } \\
2007[48] \\
(n=120)\end{array}$ & $\begin{array}{l}\text { Smith-Olinde et al. } \\
2008 \text { [49] }(n=103)\end{array}$ & $\begin{array}{l}\text { Quinn et al. } \\
2004[50] \\
(n=243)\end{array}$ & $\begin{array}{l}\text { Boulton et al. } \\
2006[51] \\
(n=79)\end{array}$ \\
\hline $\begin{array}{l}\text { Country study } \\
\text { conducted in }\end{array}$ & Hong Kong & USA & Canada & UK & USA & USA & UK \\
\hline Gender & $F: 44 \%$ & $F: 15 \%$ & $F: 63 \%$ & $F: 45 \%$ & $F: 49 \%$ & $F: 52 \%$ & $F: 41 \%$ \\
\hline Age (Mean $\pm S D ;$ Range) & $23.6 y \pm 8.5(5-53)$ & $8.6 y \pm 3.3(4-17)$ & Not reported & 7.9 y $(5-12)$ & $7.3 y \pm 1.9(5-10)$ & $10 y$ & $6.2 y \pm 1.5(3-8)$ \\
\hline Condition studied & Down syndrome & $\begin{array}{l}\text { Autistic spectrum } \\
\text { disorder }\end{array}$ & Musculoskeletal & $\begin{array}{l}\text { Hearing } \\
\text { impairment }\end{array}$ & Hearing loss & $\begin{array}{l}\text { Retinopathy of } \\
\text { prematurity }\end{array}$ & $\begin{array}{l}\text { vision impairment } \\
\text { or blindness }\end{array}$ \\
\hline \multicolumn{8}{|l|}{ HUI3 score } \\
\hline Overall & $0.55 \pm 0.27$ & $0.66 \pm 0.23$ & & & & & \\
\hline Chronic orthopaedic & $\begin{array}{l}0.47 \pm 0.23 \\
(n=11)\end{array}$ & & 0.87 & & & & \\
\hline Hearing & $\begin{array}{l}0.39 \pm 0.28 \\
(n=21)\end{array}$ & & & $0.63 \pm 0.32$ & $0.62 \pm 0.20$ & & \\
\hline Vision & $\begin{array}{l}0.47 \pm 0.29 \\
(n=50)\end{array}$ & & & & & $0.59 \pm 0.39$ & $0.34 \pm 0.43$ \\
\hline
\end{tabular}


and necessary therapeutic services should be implemented for people with DS.

Furthermore, the ability to quantify HRQoL has broad implications. It would be useful for healthcare professionals, social workers, and counselors to communicate to expectant parents about the realistic outcome of caring for someone with DS.

Various limiting factors warrant consideration. 1) For the study population, surveys were administered through HKDSA events, classes, and gatherings; therefore, the group of individuals with DS who are severely disabled or require intensive medical monitoring might not be included. This may result in surveying the healthier population, thus underestimating the self-reported health condition occurrence rate. 2) The survey was proxy-assessed by parents/caregivers and arguments regarding the reliability of proxy-results have been queried. However, it has been suggested that agreement and reliability tend to be valid if the survey was completed by close relatives [56], which in our case all respondents were parents or caregivers. 3) As a generic instrument, HUI was used in this study to assess the HRQoL of people with DS; concrete information on quality of life specifically related to DS may not have been included.

To the best of our knowledge, this is the first study which assessed and quantified the HRQoL of Chinese people with DS. The valuable dataset allows healthcare professionals, counselors, social workers, and caregivers to be alerted about the adverse impact of developmentalbehavioral problems on the overall HRQoL of people with DS. In addition, quantifiable measure of HRQoL would also facilitate longitudinal study on well-being of DS subjects and evaluation of effectiveness of intervention programs in the near future.

\section{Conclusions}

This study validated the HUI-Ch and was applied on people with DS in Hong Kong, which concluded with valuable information on the HRQoL and in relation to the chronic health problems incurred.

\section{Additional files} Additional file 1: Table S1. HUI2 Multi-Attribute Health Status Classification
System.

Additional file 2: Table S2. HUI3 Multi-Attribute Health Status Classification System.

Additional file 3: Table S3. Description of Assigned Ranges of Overal HUI2 and HUI3 Scores to Categories of Disability: None; Mild; Moderate; and Severe.

\section{Abbreviations}

HUI: Health Utility Index; HUI2/3: Health Utility Index Mark 2/ Mark 3; HUI-Ch: Chinese version of Health Utilities Index; DS: Down syndrome; HRQoL: Health-related Quality of Life; WHO: World Health Organization; TNO-AZL: Netherlands Organization for Applied Scientific Research Medical Centre; HUlnc: Health Utilities Inc:; HKDSA: Hong Kong Down Syndrome Association.
Competing interests

The authors declare that they have no competing interests.

\section{Authors' contribution}

WKYM conceived of and carried out the study and also drafted and revised the manuscript. WHSW conceived of the study, oversaw the statistical analysis and revised the manuscript. GTKM carried out the study, performed statistical analysis and revised the manuscript. YWYC translated the English Health Utility Index questionnaire into Chinese. FKWH performed statistical analysis. CBC conceived of and coordinated the study. PIP \& BHYC conceived of the study, and participated in its design and coordination and drafted and revised the manuscript. All authors read and approved the final manuscript.

\section{Acknowledgements}

We would like to thank the Hong Kong Down Syndrome Association and their members for all their efforts to make this project successful. We would also like to thank Health Utilities Inc. and their coordinators for allowing us to use the HUI questionnaires in this study.

Received: 19 March 2014 Accepted: 12 September 2014

Published online: 14 October 2014

\section{References}

1. Roizen NJ, Patterson D: Down's syndrome. Lancet 2003, 361:1281-1289.

2. Sherman SL, Allen EG, Bean LH, Freeman SB: Epidemiology of Down syndrome. Ment Retard Dev Disabil Res Rev 2007, 13:221-227.

3. Lo K, Lam S, Chan W: Down syndrome in Hong Kong. Hong Kong J Paediatr 1994, 11:104-108.

4. Leonard S, Bower C, Petterson B, Leonard H: Medical aspects of school-aged children with Down syndrome. Dev Med Child Neurol 1999, 41:683-688.

5. Van Allen MI, Fung J, Jurenka SB: Health care concerns and guidelines for adults with Down syndrome. Am J Med Genet 1999, 89:100-110.

6. Pueschel SM, Anneren G, Durlach R, Flores J, Sustrova M, Verma IC: Guidelines for optimal medical care of persons with Down syndrome. International League of Societies for Persons with Mental Handicap (ILSMH). Acta Paediatr 1995, 84:823-827.

7. Hasle H, Clemmensen $1 \mathrm{H}$, Mikkelsen M: Risks of leukaemia and solid tumours in individuals with Down's syndrome. Lancet 2000, 355:165-169.

8. Yam WK, Tse PW, Yu CM, Chow CB, But WM, Li KY, Lee LP, Fung EL, Mak PP, Lau JT: Medical issues among children and teenagers with Down syndrome in Hong Kong. Downs Syndr Res Pract 2008, 12:138-140.

9. Frid C, Drott P, Lundell B, Rasmussen F, Anneren G: Mortality in Down's syndrome in relation to congenital malformations. I Intellect Disabil Res 1999, 43(Pt 3):234-241.

10. Leonard S, Bower C, Petterson B, Leonard H: Survival of infants born with Down's syndrome: 1980-96. Paediatr Perinat Epidemiol 2000, 14:163-171.

11. Janicki MP, Dalton AJ, Henderson CM, Davidson PW: Mortality and morbidity among older adults with intellectual disability: health services considerations. Disabil Rehabil 1999, 21:284-294.

12. Hill DA, Gridley G, Cnattingius S, Mellemkjaer L, Linet M, Adami HO, Olsen $\mathrm{JH}$, Nyren O, Fraumeni JF Jr: Mortality and cancer incidence among individuals with Down syndrome. Arch Intern Med 2003, 163:705-711.

13. Glasson EJ, Sullivan SG, Hussain R, Petterson BA, Montgomery PD, Bittles AH: The changing survival profile of people with Down's syndrome: implications for genetic counselling. Clin Genet 2002, 62:390-393.

14. Esbensen AJ: Health conditions associated with aging and end of life of adults with Down syndrome. Int Rev Res Ment Retard 2010, 39:107-126.

15. Esbensen AJ, Seltzer MM, Krauss MW: Stability and change in health, functional abilities, and behavior problems among adults with and without Down syndrome. Am J Ment Retard 2008, 113:263-277.

16. Raji NS, Rao KS: Trisomy 21 and accelerated aging: DNA-repair parameters in peripheral lymphocytes of Down's syndrome patients. Mech Ageing Dev 1998, 100:85-101.

17. Roth GM, Sun B, Greensite FS, Lott IT, Dietrich RB: Premature aging in persons with Down syndrome: MR findings. AJNR Am J Neuroradiol 1996, 17:1283-1289.

18. Prasher VP, Sajith SG, Mehta P, Zigman WB, Schupf N: Plasma beta-amyloid and duration of Alzheimer's disease in adults with Down syndrome. Int J Geriatr Psychiatry 2010, 25:202-207. 
19. Zigman WB, Devenny DA, Krinsky-McHale SJ, Jenkins EC, Urv TK, Wegiel J, Schupf N, Silverman W: Alzheimer's Disease in Adults with Down Syndrome. Int Rev Res Ment Retard 2008, 36:103-145.

20. Yang Q, Rasmussen SA, Friedman JM: Mortality associated with Down's syndrome in the USA from 1983 to 1997: a population-based study. Lancet 2002, 359:1019-1025.

21. Silverman W: Down syndrome: cognitive phenotype. Ment Retard Dev Disabil Res Rev 2007, 13:228-236.

22. Van Gameren-Oosterom HB, Fekkes M, Buitendijk SE, Mohangoo AD, Bruil J, Van Wouwe JP: Development, problem behavior, and quality of life in a population based sample of eight-year-old children with Down syndrome. PLoS One 2011, 6:e21879.

23. Honaker J, King G, Blackwell M: Amelia II: A Program for Missing Data. J Stat Softw 2011, 45:1-47.

24. Bittles $\mathrm{AH}$, Glasson EJ: Clinical, social, and ethical implications of changing life expectancy in Down syndrome. Dev Med Child Neurol 2004, 46:282-286.

25. Englund A, Jonsson B, Zander CS, Gustafsson J, Anneren G: Changes in mortality and causes of death in the Swedish Down syndrome population. Am J Med Genet A 2013, 161a:642-649.

26. Newton R: Capacity to enjoy longer life. Dev Med Child Neurol 2004, 46:219.

27. Drake $H$, Reid M, Marteau T: Attitudes towards termination for fetal abnormality: comparisons in three European countries. Clin Genet 1996, 49:134-140.

28. Maddigan SL, Feeny DH, Johnson JA: Construct validity of the RAND-12 and Health Utilities Index Mark 2 and 3 in type 2 diabetes. Qual Life Res 2004, 13:435-448.

29. Grootendorst P, Feeny D, Furlong W: Health Utilities Index Mark 3: evidence of construct validity for stroke and arthritis in a population health survey. Med Care 2000, 38:290-299.

30. Horsman J, Furlong W, Feeny D, Torrance G: The Health Utilities Index (HUI): concepts, measurement properties and applications. Health Qual Life Outcomes 2003, 1:54.

31. Down JL: Observations on an ethnic classification of idiots. 1866. Ment Retard 1995, 33:54-56.

32. Furlong WJ, Feeny DH, Torrance GW, Barr RD: The Health Utilities Index (HUI) system for assessing health-related quality of life in clinical studies. Ann Med 2001, 33:375-384

33. Torrance GW, Feeny DH, Furlong WJ, Barr RD, Zhang Y, Wang Q: Multiattribute utility function for a comprehensive health status classification system. Health Utilities Index Mark 2. Med Care 1996, 34:702-722.

34. Torrance GW, Furlong W, Feeny D, Boyle M: Multi-attribute preference functions. Health Utilities Index. Pharmacoeconomics 1995, 7:503-520.

35. Wang Q, Furlong W, Feeny D, Torrance G, Barr R: How robust is the Health Utilities Index Mark 2 utility function? Med Decis Making 2002, 22:350-358.

36. Department of Paediatrics and Adolescent Medicine, The University of Hong Kong, School of Public Health, The University of Hong Kong: Child Health Survey 2005-2006. Hong Kong Special Administrative Region, China: Surveillance and Epidemiology Branch, Centre for Health Protection, Department of Health; 2009.

37. Henderson A, Lynch SA, Wilkinson S, Hunter M: Adults with Down's syndrome: the prevalence of complications and health care in the community. Br J Gen Pract 2007, 57:50-55.

38. Coe DA, Matson JL, Russell DW, Slifer KJ, Capone GT, Baglio C, Stallings S: Behavior problems of children with Down syndrome and life events. J Autism Dev Disord 1999, 29:149-156.

39. Trois MS, Capone GT, Lutz JA, Melendres MC, Schwartz AR, Collop NA Marcus CL: Obstructive sleep apnea in adults with Down syndrome. J Clin Sleep Med 2009, 5:317-323.

40. Schafer JL: Analysis of incomplete multivariate data. London: Chapman \& Hall; 1997

41. Feng $Y$, Bernier J, McIntosh C, Orpana H: Validation of disability categories derived from Health Utilities Index Mark 3 scores. Health Rep 2009, 20:43-50.

42. Felder-Puig R, Frey E, Sonnleithner G, Feeny D, Gadner H, Barr RD, Furlong W, Topf R: German cross-cultural adaptation of the Health Utilities Index and its application to a sample of childhood cancer survivors. Eur J Pediatr 2000, 159:283-288.

43. Szecket N, Medin G, Furlong WJ, Feeny DH, Barr RD, Depauw S: Preliminary translation and cultural adaptation of Health Utilities Index questionnaires for application in Argentina. Int J Cancer Supp/ 1999, 12:119-124.

44. Costet N, Le Gales C, Buron C, Kinkor F, Mesbah M, Chwalow J, Slama G: French cross-cultural adaptation of the Health Utilities Indexes Mark 2 (HUI2) and 3 (HUI3) classification systems. Clinical and Economic Working Groups. Qual Life Res 1998, 7:245-256.

45. Guillemin F, Bombardier C, Beaton D: Cross-cultural adaptation of health-related quality of life measures: literature review and proposed guidelines. J Clin Epidemiol 1993, 46:1417-1432.

46. Tilford JM, Payakachat N, Kovacs E, Pyne JM, Brouwer W, Nick TG, Bellando J, Kuhlthau KA: Preference-based health-related quality-of-life outcomes in children with autism spectrum disorders: a comparison of generic instruments. Pharmacoeconomics 2012, 30:661-679.

47. Manuel DG, Schultz SE, Kopec JA: Measuring the health burden of chronic disease and injury using health adjusted life expectancy and the Health Utilities Index. J Epidemiol Community Health 2002, 56:843-850.

48. Petrou S, McCann D, Law CM, Watkin PM, Worsfold S, Kennedy CR: Health status and health-related quality of life preference-based outcomes of children who are aged 7 to 9 years and have bilateral permanent childhood hearing impairment. Pediatrics 2007, 120:1044-1052.

49. Smith-Olinde L, Grosse SD, Olinde F, Martin PF, Tilford JM: Health state preference scores for children with permanent childhood hearing loss: a comparative analysis of the QWB and HUI3. Qual Life Res 2008, 17:943-953.

50. Quinn GE, Dobson V, Saigal S, Phelps DL, Hardy RJ, Tung B, Summers CG, Palmer EA: Health-related quality of life at age 10 years in very low-birthweight children with and without threshold retinopathy of prematurity. Arch Ophthalmol 2004, 122:1659-1666.

51. Boulton M, Haines L, Smyth D, Fielder A: Health-related quality of life of children with vision impairment or blindness. Dev Med Child Neurol 2006, 48:656-661.

52. Mitchell RB, Call E, Kelly J: Ear, nose and throat disorders in children with Down syndrome. Laryngoscope 2003, 113:259-263.

53. Park AH, Wilson MA, Stevens PT, Harward R, Hohler N: Identification of hearing loss in pediatric patients with Down syndrome. Otolaryngol Head Neck Surg 2012, 146:135-140.

54. Van Schrojenstein Lantman-De Valk HM, Metsemakers JF, Haveman MJ, Crebolder HF: Health problems in people with intellectual disability in general practice: a comparative study. Fam Pract 2000, 17:405-407.

55. Patja K, livanainen $M$, Vesala $H$, Oksanen $H$, Ruoppila I: Life expectancy of people with intellectual disability: a 35-year follow-up study. J Intellect Disabil Res 2000, 44(Pt 5):591-599.

56. Andresen EM, Vahle VJ, Lollar D: Proxy reliability: health-related quality of life (HRQoL) measures for people with disability. Qual Life Res 2001, 10:609-619.

doi:10.1186/s12955-014-0144-x

Cite this article as: Mok et al:: Validation and application of health utilities index in Chinese subjects with down syndrome. Health and Quality of Life Outcomes 2014 12:144.

\section{Submit your next manuscript to BioMed Central and take full advantage of:}

- Convenient online submission

- Thorough peer review

- No space constraints or color figure charges

- Immediate publication on acceptance

- Inclusion in PubMed, CAS, Scopus and Google Scholar

- Research which is freely available for redistribution 